\title{
The Teacher and Peer Intervention for Pre-Service Mathematics Teachers on the Validity of Mathematical Models
}

\author{
Zeynep Cakmak Gurel ${ }^{1 *}$ (D), Mehmet Bekdemir ${ }^{1}$ (D)
}

${ }^{1}$ Faculty of Education, Erzincan Binali Yildirim University, TURKEY
*Corresponding Author: zcakmak@erzincan.edu.tr

Citation: Cakmak Gurel, Z., \& Bekdemir, M. (2022). The Teacher and Peer Intervention for Pre-Service Mathematics Teachers on the Validity of Mathematical Models. Pedagogical Research, 7(2), em0120. https://doi.org/10.29333/pr/11800

\begin{tabular}{|c|c|}
\hline ARTICLE INFO & ABSTRACT \\
\hline Received: 4 Jan. 2022 & The aim of this study is to investigate the types of teacher and peer interventions to test the validity of modelling \\
\hline Accepted: 16 Feb. 2022 & $\begin{array}{l}\text { along with the modelers' reactions to these interventions. A teaching experiment was employed in the study. } \\
\text { Forty-five pre-service secondary school mathematics teachers participated in the research. As a data collection } \\
\text { tool, a worksheet was prepared by taking the monthly average temperature values of the last five years from the } \\
\text { Meteorology Directorate of the province in which the study was conducted. At the end of the mathematical } \\
\text { modelling process, teacher and peer interventions were carried out. The types of teacher and peer interventions } \\
\text { were categorized. The reasons for intervening in the modelling process by both the teacher and peers were } \\
\text { insufficient explanations and student error. In addition, the teacher intervened to advance the process. The } \\
\text { teacher intervened for diagnosis, advice and feedback, and the peers intervened for diagnosis and feedback in this } \\
\text { process. While teacher intervention occurred at the stage of mathematical model and results, peer intervention } \\
\text { occurred at the stage of testing the real model and result. The participants returned to revise their real model, } \\
\text { mathematical model and results. In the modeling process, while peer support may be sufficient to test the validity } \\
\text { of the real model and real results, teacher support is required to test the validity of the mathematical model and } \\
\text { its results. }\end{array}$ \\
\hline
\end{tabular}

Keywords: mathematical modelling, peer intervention, teacher intervention, validity

\section{INTRODUCTION}

Mathematical modelling was formerly used in applied sciences such as physical chemistry or engineering. After this concept began to be used in mathematics education, it was included in the mathematics curricula of several countries such as the USA, Germany, and Turkey (Blomhøj \& Kjeldsen, 2006; Blum \& Borromeo Ferri, 2009; Common Core State Standards Initiative [CCSI], 2010; Lingefjärd, 2006; Ministry of National Education [MoNE], 2013). To explain the mathematical modelling concept, first the concept of model and mathematical model should be defined. A model is defined as a tool that represents some aspects, not all, of real-life situations, whereas a mathematical model is used to express the real world with mathematical representations (Greefrath \& Vorhölter, 2016). While models are any physical materials or simulations that show how a situation works, mathematical models can be mathematical tools such as equations or graphs (Borromeo Ferri, 2006; NCTM, 2000).

Mathematical modelling represents a cyclic process bridging between the real world and the mathematics world, defined as transporting a real-world situation or problem into the world of mathematics and then making interpretations of potential realworld solutions (Blum \& Borromeo Ferri, 2009; Czocher, 2017; Lesh \& Doerr, 2003). This modelling process can iterate with new or different variables and assumptions to develop or change the models (CCSI, 2010). Blum and Leiß (2007) have outlined this type of cyclical mathematical modelling process and the modelling cycle they developed (see Figure 1 ) is foundational for this study. Similarly, according to Borromeo Ferri (2010) and Durandt and Lautenbach (2020), this kind of cycle was chosen because it is sufficiently detailed, common in education studies, a suitable and helpful tool for analyzing modelling processes.

The mathematical modelling process demonstrated in Figure 1 is defined in six stages. These stages are the "real situation", "situation model", "real model", "mathematical model", "mathematical results", and "real results". Mathematical modelling competence (MMC) includes competencies of identifying, mathematization, analyzing, interpreting and testing the model's validity. Also, modelers check the content and properties of the models obtained, compare models, work with models, modify or develop models in a cyclical way, evaluate models and test models' validity (Blum, 2002; Niss et al., 2007). When the studies are examined, it was found that students had some problems in constructing the real model by defining the variables of the situation and making assumptions (Blum, 2011; Frejd \& Ärlebäck, 2011; Ji, 2012; Maaß, 2006; Schaap et al., 2011), creating a mathematical model (Frejd \& Ärlebäck, 2011; Gurel, 2018; Ji, 2012; Maaß, 2007) and calculating mathematically (Galbraith \& Stillman, 2006; 


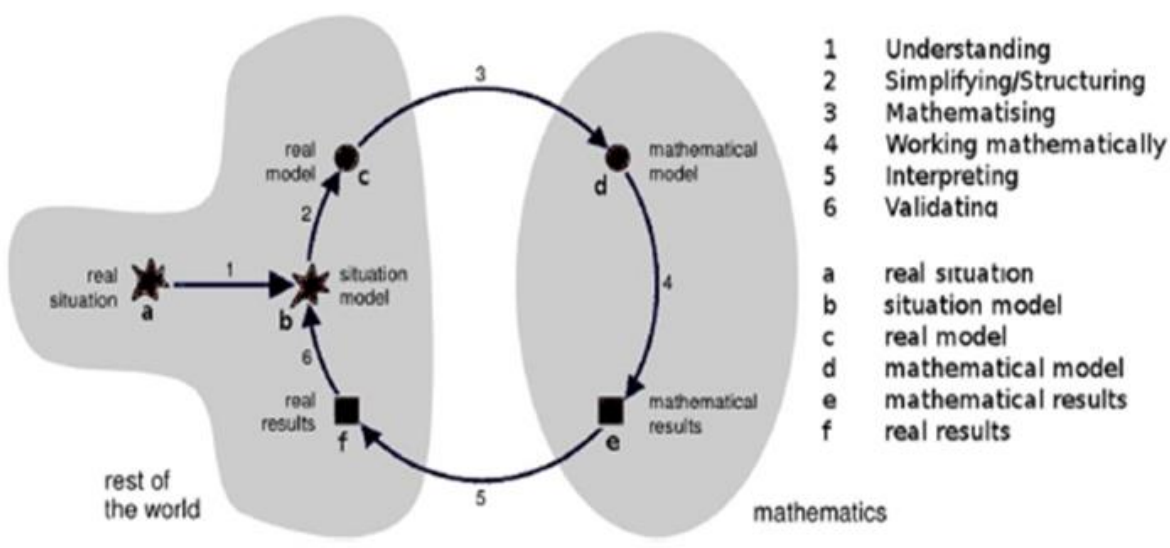

Figure 1. Mathematical modelling process according to Blum and Leiß (2007)

Turker et al., 2010). In some studies, it was found that the largest deficiency in modelling process was verifying and testing models' validity competencies (Biccard \& Wessels, 2011; Bukova Guzel, 2011; Gatabi \& Abdolahpour, 2013; Gurel, 2018; Turker et al., 2010).

In recent years, different learning environments have been designed to develop the MMC and the effects of these have been investigated (Brand, 2014; Grünewald, 2012). As these practices were examined, it was determined that various factors contributed to the development of modelling competence such as group work (Biccard \& Wessels, 2011; Maaß, 2006), the individual frequently encountering modelling situations (Anhalt \& Cortez, 2016), having a basic knowledge of the modelling concept (Dede \& Yilmaz, 2013) and designing a learning environment based on a holistic or atomic approach (Brand, 2014; Grünewald, 2012; Gurel, 2018; Kaiser \& Brand, 2015). Although these designed learning approaches generally enable the students to develop modelling competencies, the effect of approaches on the development of competencies like verification, testing models' validity, revising the model, and developing the model remained quite low (Grünewald, 2012; Guc, 2015; Gurel, 2018). Czocher (2018) emphasizes that validity should be discussed during each of the modeling stages. Therefore, the validity is closely related to each of the other modeling stages.

The present study focuses on the competency related to test models' validity by classifying teacher and peers (i.e., that of other participants) intervention. The concept of intervention is used to support individual learning and problem-solving process of students as this kind of assistance of the teacher (Stender \& Kaiser, 2015). An intervention is usually a dialogue between a teacher and student (e.g., Wischgoll et al., 2015). The concept of intervention in this study is not used with connotations of criticism or judgement, but rather to denote support for positive change and development with a dialogue between a teacher and student. As the studies on intervention types are taken into consideration (Anghileri, 2006; Kaiser \& Stender, 2013; Leiß \& Wiegand, 2005; Pol et al., 2010; Tropper et al., 2015), some research indicates that teacher intervention types have a few general classifications. Stender and Kaiser (2015) analyzed the different levels of support. The first level involves the motivating help, the second level involves the positive feedback, and the third level involves the strategic support. The fourth level is the content-related strategic support, while the fifth level is the content-related support. Tropper et al. (2015) present an in-depth analysis in this field and have classified teacher intervention types under three categories. The first type is the reason for intervention and includes students making errors, a student asking questions or having difficulty in the solution process, or even teacher expectations. The second type is the area of intervention and includes general support, strategic support, and motivational support. The third type is the intention of the intervention and includes the cases of intention/diagnosis, giving direct feedback and giving indirect suggestions or hints. These researchers have proposed reconceptualizing teacher intervention in mathematical modeling activities. Specially, this study aimed to explain teachers (and peers) intervention at stage of models' validity. In addition, this study, unlike other studies, focused on intervention at the end of the modeling process. Because an intervention can take place at the beginning, in the middle or at the end of task (Holton \& Thomas, 2001).

The studies conducted by Stender and Kaiser (2015) and Tropper et al. (2015) were on teacher intervention types but it does not investigate teacher and peer interventions simultaneously. Our study classifies peer interventions in addition to teacher intervention and details the differences and similarities between them. Furthermore, it is believed that it is significant to know the change that occurred in the modelling process because of teacher or peer intervention. Revealing how students behave in modelling cycles after an intervention may give teachers new perspectives and new tools. On the other hand, it can give unique information about how researchers/teachers should intervene with the validating of the model in various modelling activities. In this respect, it is thought that the study will contribute to the limited literature on the behaviors and instructional approaches of researchers/teachers in the mathematical modelling.

The aim of this study is to investigate the types of teacher and peer interventions related to test models' validity along with the modelers' reactions to these interventions at the end of the mathematical modelling process. The research questions:

1. What are the types of teacher and peer interventions for testing the validity of the real model, mathematical model, mathematical results and real results?

2. How do participants act in the modelling cycle after the intervention? 


\section{METHOD}

\section{Research Design}

The teaching experiment was employed in this study. The teaching experiment is defined as the process of monitoring the knowledge of the student first-hand in the teaching process, obtaining information about him/her and realizing the change/development in the student's overall understanding and reasoning (Steffe \& Thompson, 2000). This method was selected as it allows us to directly see the types of interventions that teachers and peers implement during the modelling process. Also, this method was chosen to reveal how the participants respond in the modelling cycle because of teacher and peer intervention. To show this, dialogues including questions, criticism or comments throughout the process and the patterns of responding in the modelling cycle were included in the study.

\section{Participants}

The study group consisted of 45 (female: 25; male: 20) pre-service secondary school mathematics teachers who were in their fourth year of study at the Faculty of Education in a medium-sized province of eastern Turkey for the fall term of the 2018-2019 academic year. The average age of the participants was 22.5. These pre-service teachers initially entered the department following their central placement exam immediately after graduating from high school. After four years at university, they graduate as preservice mathematics teachers. During their education, in addition to taking theoretical and practical courses in the department, they do internships at the secondary schools in the city where they are located for two semesters. They take theoretical courses such as algebra, analysis, statistics, analytical geometry, general physics, applied mathematics teaching, material design, measurement and evaluation, and problem-solving. These pre-service teachers did not take any courses directly related to the inclass application of mathematical modelling. Furthermore, they did not encounter mathematical modelling applications in the secondary schools where they did their internship. As mathematical modelling is quite a new subject in the secondary school curriculum in Turkey, it is not frequently used by teachers. Also, two teachers and one observer took part in the implementation process. The teachers and observer had previously received training in modelling and teaching experimentation. In addition, they had experience of many different modelling applications with students at the secondary school and university levels.

\section{Data Collection Process}

There were three stages in the implementation. The first was the process of sharing information about the mathematical model and modelling. The second stage was the group work process in which the modelling activity is carried out while the third was the process of sharing the created models. Before the modelling activity started, information was shared with the pre-service teachers in a three-hour lesson regarding mathematical models, mathematical modelling, the modelling process and modelling skills. The purpose of this training was to help understanding of the concepts used in the modelling process by these pre-service teachers. Specifically, they were trained on concepts in this process such as mathematical models, variables, and assumptions. Then, the groups work process began.

During the group work, the pre-service teachers were divided into groups of six or seven persons according to their own choosing. Thus, seven groups were created. Next, tables of temperature were distributed to groups. The modelling task was arranged under the following heading: "Create a model of the temperature predictions for next year taking consideration the temperature values between 2012 and 2017." The groups evaluated this situation during five lessons (a lesson lasts 50 minutes) and created their models. Since they had participated in similar activities before, they conducted their modeling processes without asking questions. The teachers and observer did not directly interfere with the participants' modelling process. As the group work was taken as unit of the data analysis, the findings were presented under group 1, group $2, \ldots$, group 7 codes.

In the process called "sharing of created models", which is the third stage, each group was asked to share their created model with the whole class. Teacher and peer interventions were then carried out on these models. In this process, questions or comments about the groups' models were directed by the teachers and peers. Applying this process had two purposes. The first was to understand the reasoning process of the participants, to uncover their assumptions related to the model, see how they define the relationships between the variables and how they make sense of the situation. The second reason was to reveal in what direction pre-service teachers move throughout the modelling cycle by directing questions and comments about the developed model. In this context, discussions, such as asking, evaluating and interpreting, were made among the group members, teachers and peers about the models that were put forth by the various groups. As the groups had participated in similar activities before, they got used to making presentations. The peers and teachers voluntarily and freely asked questions and shared evaluations to the group who presented its model. The peers were comfortable and democratic in commenting other group's model because they had participated in such process before. When peer assessments are voluntary, students are more autonomous and motivated and can benefit more from the process (Li et al., 2019). All groups were given equal time to share their models. Since each group's model is different (arithmetic mean and least squares method), the teacher applied adaptive intervention to them. Therefore, there was no relationship between the first presenting group and the last presenting group in terms of intervention. This entire sharing process, which was recorded on video, continued for approximately four hours.

\section{Real situation applied in the research}

The fact that a mathematical task can be mapped onto real-life situations and real-world data is a significant feature of mathematical modelling. Within the scope of a semester-long mathematical modelling course, real-life data were constantly being engaged by the teaching candidates such as earthquake location and intensity according to the years, the number of annual passengers arriving and leaving at a designated airport and the average annual weather temperatures. As a typical example, a 12- 
Table 1. The explanations of the codes related to the intervention types (Adapted from Tropper et al., 2015)

\begin{tabular}{|c|c|}
\hline \multicolumn{2}{|l|}{ Intervention reason } \\
\hline Insufficient explanation & $\begin{array}{l}\text { Intervention due to a lack of explanation in cases where the explanation expressed by the modelers is not understood, } \\
\text { considered insufficient, or if a student error has not been determined yet }\end{array}$ \\
\hline Advancing the process & Complete one or more steps in the extended modelling cycle of the modelers or intervene to overcome an obstacle \\
\hline Student error & Intervention due to mistakes or missteps of the modeler during the process \\
\hline \multicolumn{2}{|c|}{ Intervention intention } \\
\hline Diagnosis & Diagnostic intervention is used to understand how modelers make sense/evaluate their situation throughout process \\
\hline Feedback & Interventions involving positive, negative or neutral feedback \\
\hline Hint & Recommendation statements are given to overcome a problem \\
\hline \multicolumn{2}{|l|}{ Intervention area } \\
\hline \multicolumn{2}{|l|}{ Situation model } \\
\hline \multicolumn{2}{|l|}{ Real model } \\
\hline Mathematical model & Intervention at any stage of the modelling cycle \\
\hline \multicolumn{2}{|l|}{ Mathematical results } \\
\hline Real results & \\
\hline
\end{tabular}

hour module called the temperature estimation activity was selected in this type of study. After receiving the necessary permission, data regarding the 12-month average temperature and the maximum and minimum values were taken from the Meteorological Administration of the province where the study was conducted. These data related specifically to the years of 20122017 (the year 2018 was not included since the event was held in 2018) and it was arranged together and shown in the table. Thus, a table was prepared that shows real temperature values broken down into months (Appendix). The table was then examined by two mathematics educators for reliability. The aim was to teach mathematical modelling directly with the modelling activity rather than teaching any mathematical concept or theory. During the mathematical modelling process, the participants used mathematical concepts such as "arithmetic mean, range, maximum and minimum values, standard deviation, normal distribution, equation, slope, graph, and least squares method."

\section{Data Analysis}

Video recordings in the study constitute the data for this research. The video recordings of the pre-service teachers were transcribed, and this transcript was inspected and verified. During the data analysis, there was a focus on the teacher, peer and group dialogues from the transcribed camera recordings. The dialogues extracted from the video recordings were coded using qualitative content analysis (Mayring, 2015). In this study, three intervention types were defined theoretically. Theoretical basis is structured with the deductive category system adapted from Tropper et al. (2015). The reason for selecting the analysis method is to classify the types of intervention in a very detailed and systematic manner. In Table 1, these types of interventions are divided into three categories: reason for intervention, intention, and area. The codes and indicators are also given under these categories.

In the study, a dialogue was evaluated in terms of the intervention reason, the intervention intention and the intervention area categories. Two codes as "advancing the process" and "student error" in the category of intervention reason generated by Tropper et al. (2015) were observed and an extra code called "insufficient explanations" also appeared. Three codes as diagnosis, feedback and hint in the category of Intervention Intention occur in this study. Unlike Tropper et al. (2015)'s study, the category of Intervention Area was evaluated in the context of the stages of the modelling cycle by Blum and Leiß (2007). The reason for the differences between the two studies is thought to be from differing points of time when the interventions occurred. In the study conducted by Tropper et al. (2015), teacher interventions emerged at the solution stage of the modelling activities during group work, but in this study, teacher and peer interventions emerged at the stage of model sharing after participants performed their modelling activities. In short, the differences of model sharing from this study in comparison to the study of Tropper et al. (2015) may come from when the interventions occurred during the process. The reason why there is no intervention in the group work process in this study is that there was a desire to observe how the participants respond in the modelling cycle with teacher and peer interventions.

Group dialogues were transcribed by two researchers who are teachers in this study. The dialogue sections that related to the validity of the models and results were selected. A total of 18 validity-related interventions and 9 (participants') reactions to the interventions were identified. It was decided by two mathematics educators whether these dialogues were about validity of the real model, the mathematical model, the mathematical result and the real result. There is a lack of intervention during the stage of situation model. This is thought to be due again to the intervention taking place during the model sharing stage, not during the model producing stage. The dialogues were interpreted in terms of what the type of intervention was, with whom the dialogue was carried out, and which stage the participants progress in the modelling cycle after the interventions.

\section{Teacher/Observer/Peer Role}

One observer and two teachers participated in the study. During the implementation, the observer is responsible for recording the "sharing of created models" process. Teachers, on the other hand, asked questions, provided comments or criticism while the mathematical models were being shared in order to improve and create a better understanding of the mathematical models that the participants created as a group. The teachers have the role of guiding the process during the model sharing stage by asking for example "do you mean...?" They also ask questions about groups' reasons for using a particular model and results or request a fuller explanation from the participants. This allows the researcher to avoid directly or indirectly guiding the discussion with their expertise as much as possible. However, peers can freely direct their questions and criticisms to the groups presenting their models without guidance from the teachers. 


\section{Intervention Reason}

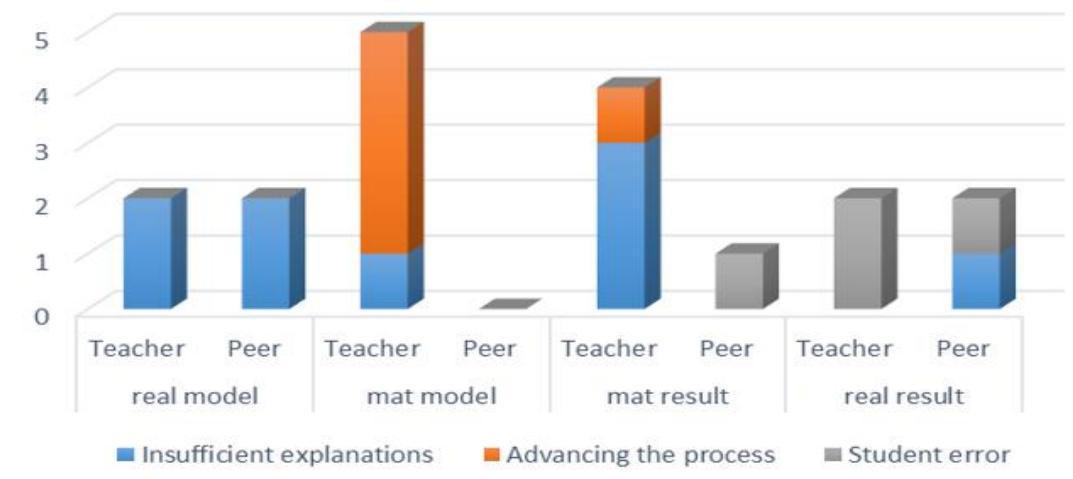

Figure 2. Frequency of intervention reason of teacher and peer during the mathematical modelling

\section{FINDINGS}

The aim of this study is to put forth the types of teacher and peer interventions and how pre-service teachers behave after an intervention in the modelling cycle, during the process of testing the real model, the mathematical model, the mathematical result, and the real result validities.

The findings for the first objective titled "What are the types of teacher and peer interventions for the process of testing the validity of the real model, mathematical model, mathematical results, and real results?" are presented in the following. The types of teacher and peer interventions that emerged during the model sharing of the groups were classified into categories. In the study, the interventions were evaluated separately and divided under three headings: reason, intention, and area.

"Intervention reason category" was identified with the codes of insufficient explanations, advancing the process, and student error in Figure 2.

It was determined that the teacher interventions were caused by insufficient explanations ( $f: 6$ intervention), to advance the process ( $f: 5$ intervention) and student error ( $f: 2$ intervention), whereas the reasons for peer interventions were more limited to insufficient explanations ( $f: 3$ intervention) and student error ( $f: 2$ intervention). While the intervention due to "insufficient explanations" takes place throughout the modeling cycle, the intervention based on "advancing the process" was carried out by only the teachers in the mathematical model and mathematical result stages. An example dialogue for the intervention made due to "insufficient explanations" in the real model is given below.

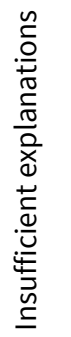

Group 5: Yes, the data we obtained shows us that. For instance, let me say the spring $(11.1,13.9$, 12.4, 10.4, 11.6, and 10.7) are all close to each other. There is no extra 2-degree increase or 2-degree decrease in the data. The values in the data are very close to each other.

Peer: ...Should there be a maximum increase of 2 degrees to used arithmetic mean in model?

Group 5: We did not specify a limit ... We made our decision by taking a brief look at data ... The standard deviation of the data could be calculated for the closeness value.

An example dialogue for the intervention made due to "advancing the process" in the mathematical model is given below.

Group 5: If this is a 10-year data we have, 7th year plus 8th year plus 9th year plus 10th year divided by 10 , like this ...

Teacher: ...I think that is not a model [pointing the expression $((1 .+2 .+3 .+4 .+5 .+6) / 6)$.$] . For$ instance, the numbers have no meaning for me.

Group 5: We found the average values...

Teacher: ... Right but now I don't know what to put there.

Group 5: Hmm... I understand, let's write it properly then... (Writes group model with mathematical symbols)

An example dialogue for the intervention made due to "student error" in the real result is given below. 


\section{Intervention Intention}

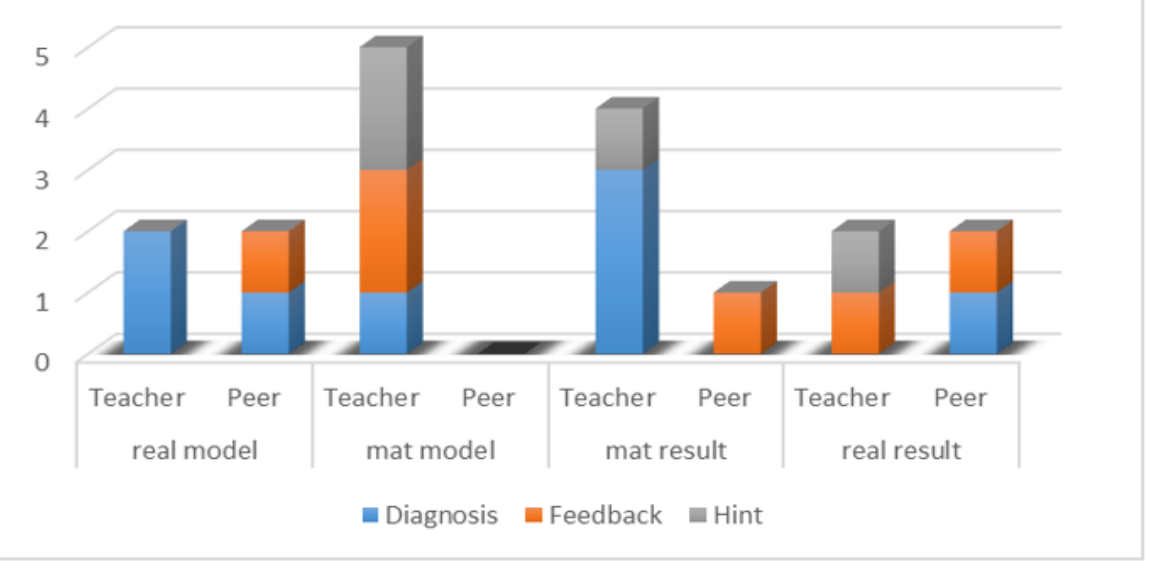

Figure 3. Frequency of intervention intention of teacher and peer during the mathematical modelling

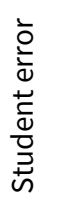

Peer: (This model means) it would never snow in 2020. For instance, we would then encounter 30-degree celsius in the winter in $2025 \ldots$

Group 1: This is not a definitive result anyway... We only predict the degree changes here (for 2019 years) ... (Group 1 turned to the mathematical model)

"Intervention intention category" was identified with the codes of diagnosis, hint, and feedback in Figure 3.

When evaluating teacher interventions, the most frequent intention was in the diagnostic code ( $f: 6$ interventions), followed by intentions of giving hint code ( $f: 4$ interventions) and feedback code ( $f: 3$ interventions). However, peers intervened mostly with feedback code ( $f: 3$ interventions) and diagnostic code ( $f: 2$ interventions) and the hint code did not appear. An example of a diagnostic code in the mathematical result is given below.

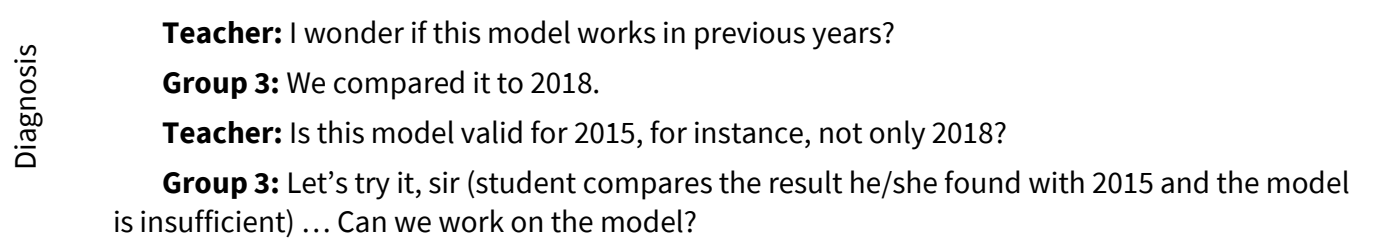

An example of the intervention made to give feedback in the real model is given below.

Group 6: There was a decrease in temperature in winter and an increase in summer in 2016. The reason for this is an ocean phenomenon called EL-NINO. Therefore, prediction for future years can be done by looking at the data from previous years.

Peer: ... There is no ocean adjacent to our country, so that type of offshore breeze does not influence us.

Group 6: ... This phenomenon affects the whole world. In other words, we observe such a change in 2016 as it affects entire regions, rather than a specific region.

An example of the intervention made to give a hint in the mathematical model is given below. 


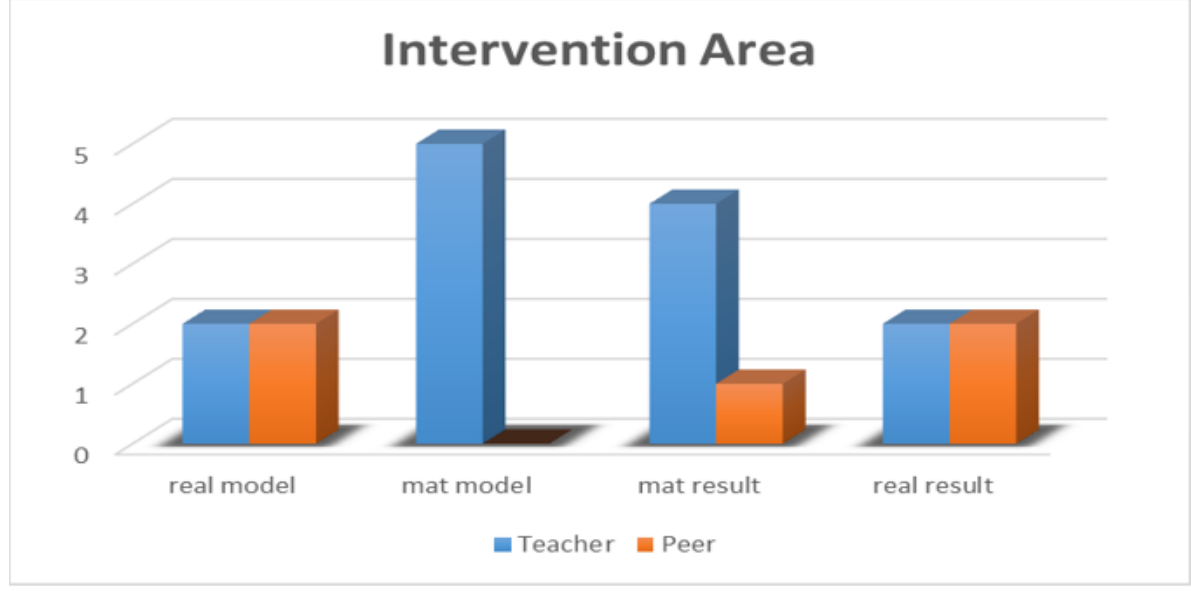

Figure 4. Frequency of intervention intention of teacher and peer during the mathematical modelling

Teacher: ...Can you write the model there? Its general formula?... What will happen in 2020-2021?

Group 1: (Explaining mathematical algorithm)

Teacher: OK. Let's write it with the formula.

Group 1: (they were thinking and writing the model)

Last six years' average- the real value in 2018=Difference

Last six years' average- Difference =Estimated value in 2019.

"Intervention area category" was identified with the codes of real model, mathematical model, mathematical result and real result in Figure 4.

In terms of the intervention area, it was determined that teacher interventions occurred during the entire modelling cycle, and peer interventions were generally at the stage of testing the validity of the real model and results. A dialogue of the real result is given below.

Group 4: ...We found the slope difference. It decreased by about 0.60 as we saw. Then we say that it will gradually decrease by $0.60-0.60-0.60$ in the following years.

Peer: Then, will the temperature according to the slope of the graphic decrease constantly?

Group 4: ... It will decrease continuously, but the slope decreases and so the temperature does not decrease by $0.60-0.60$.

The findings for the second objective titled "How do participants act and respond in the modelling cycle after the intervention?" are summarized in Table 2 and Figure 5.

Some dialogues emerged in this study that particularly addressed questions such as "Are the real model, mathematical model, mathematical results and real results mathematically valid? Are they valid in real life? Are they consistent with the data set? Could they be generalized?" In these situations, it was determined that interventions were made to discuss the validity, generalizability and consistency of the real model, mathematical model, mathematical result and the real result in terms of mathematics and reallife in this study. The real model was investigated in terms of both its mathematical validity and real-life validity on Table $\mathbf{2}$. Here, the validity of the real model is evaluated together with the validity of the variables and assumptions. The mathematical model was adopted as the mathematical concept such as arithmetic mean, equation, slope and graph, et cetera used for temperature prediction. The validity of the mathematical model was evaluated by the generalizability and mathematical validity. Then, the validity of the mathematical result was evaluated according to the consistency of the results with the data set. Finally, the validity of the real result was evaluated by both its real-life validity and mathematical validity.

Figure 5 shows how pre-service teachers act in the modelling cycle after intervention. It was determined that the participants either accepted or revised the real model, mathematical model, mathematical result and the real result after the intervention. They typically remained at the same stage in order to make revisions to the real model and the mathematical model. Furthermore, to revise the mathematical result and the actual result, it was also observed that at times they returned to the previous stages (especially the mathematical model) in the modelling cycle. 
Table 2. Teacher and peer intervention and pre-service teachers' behaviors after intervention

\begin{tabular}{|c|c|c|c|}
\hline Cycle & Intervention & Instance & $\begin{array}{l}\text { Behaviors } \\
\text { after the } \\
\text { intervention* }\end{array}$ \\
\hline \multirow[b]{2}{*}{ Real model } & $\begin{array}{l}\text { Is the real model valid } \\
\text { mathematically? }\end{array}$ & $\begin{array}{l}\text { Peer: Should there be a maximum increase of } 2 \text { degrees to used arithmetic mean in model? } \\
\text { Group 5: The standard deviation of the data could be calculated for the closeness value. }\end{array}$ & $\mathrm{R} 1$ \\
\hline & $\begin{array}{l}\text { Is the real model valid in real } \\
\text { life? }\end{array}$ & $\begin{array}{l}\text { Peer: ... There is no ocean adjacent to our country, so that type of offshore breeze does not } \\
\text { influence us. } \\
\text { Group 6: ... We observe such a change in } 2016 \text { as it affects entire regions, rather than a } \\
\text { specific region. }\end{array}$ & $\mathrm{R} 2$ \\
\hline \multirow{2}{*}{$\begin{array}{l}\text { Mathematical } \\
\text { model }\end{array}$} & $\begin{array}{l}\text { Can the mathematical } \\
\text { model be generalized? }\end{array}$ & $\begin{array}{l}\text { Teacher: Can you write the model there? Its general formula? Let's write it with the formula } \\
\text { Group 1: (they were thinking and writing the model) } \\
\text { Last six years' average- the real value in 2018=Difference } \\
\text { Last six years' average- Difference =Estimated value in } 2019\end{array}$ & R3 \\
\hline & $\begin{array}{l}\text { Is the mathematical model } \\
\text { valid mathematically? }\end{array}$ & $\begin{array}{l}\text { Teacher: I think that is not a model [pointing the expression }((1 .+2 .+3 .+4 .+5 .+6 .) / 6)] . \text { For } \\
\text { instance, the numbers have no meaning for me... } \\
\text { Group 5: Hmm... I understand, let's write it properly then... (Writes group model with } \\
\text { mathematical symbols) }\end{array}$ & $\mathrm{R} 4$ \\
\hline \multirow{3}{*}{$\begin{array}{l}\text { Mathematical } \\
\text { result }\end{array}$} & \multirow{3}{*}{$\begin{array}{l}\text { Is the mathematical result } \\
\text { consistent with the data set? }\end{array}$} & $\begin{array}{l}\text { Teacher: I wonder if this model works in previous years?... } \\
\text { Group 3: Let's try it, sir (student compares the result he/she found with } 2015 \text { and the model } \\
\text { is insufficient) ... Can we work on the model }\end{array}$ & R5 \\
\hline & & $\begin{array}{l}\text { Teacher: I'm curious about one thing. Did you check these in the data? ... } \\
\text { Group 4: (Students try for 2015.) I found same result with a very small difference. }\end{array}$ & R6 \\
\hline & & $\begin{array}{l}\text { Peer: ... Did they misread or did we? Yes, } 2016 \text { winter is a bit cold compared to others } \\
\text { according to the data. Wasn't the summer hotter than average? } \\
\text { Gruoup 6: (group checked for the relationship between variables) ... Let me correct it ... } \\
\text { While a temperature drop was observed in the winter, the summer was not affected much. }\end{array}$ & $\mathrm{R} 7$ \\
\hline \multirow{2}{*}{ Real result } & $\begin{array}{l}\text { Is the real result valid in real } \\
\text { life? }\end{array}$ & $\begin{array}{l}\text { Peer: (This model means) it would never snow in } 2020 . \\
\text { For instance, we would then encounter } 30 \text {-degree celsius in the winter in } 2025 \ldots \\
\text { (Group } 1 \text { turned to the mathematical model) }\end{array}$ & $\mathrm{R} 8$ \\
\hline & $\begin{array}{l}\text { Is the real result valid } \\
\text { mathematically? }\end{array}$ & $\begin{array}{l}\text { Peer: Then, will the temperature according to the slope of the graphic decrease constantly? } \\
\text { Group 4: ... It will decrease continuously, but the slope decreases and so the temperature } \\
\text { does not decrease }\end{array}$ & R9 \\
\hline
\end{tabular}

${ }^{\star}$ It is explained in the modeling cycle in Figure 5

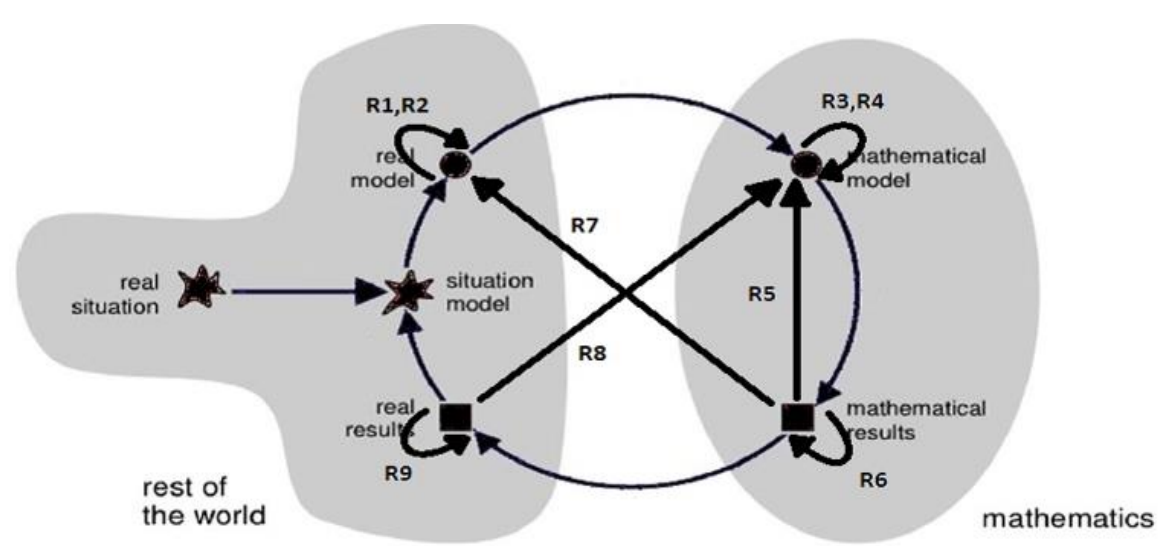

Figure 5. Pre-service teachers' behaviors in the modelling cycle after teacher and peer intervention. R1: Revision in the real model with intervention regarding the real model; R2: Verification in the real model with intervention regarding the real model; R3 Revision in the mathematical model with intervention regarding the mathematical model; R4: Revision in the mathematical model with intervention regarding the mathematical model; R5: Revision in the mathematical model with intervention regarding the mathematical results; R6: Verification of the mathematical results with intervention regarding the mathematical results; R7: Revision in the real model with intervention regarding the mathematical results; R8: Revision in the mathematical model with intervention regarding the real results; R9: Verification of the real results with intervention regarding the real results

\section{RESULTS}

This paper focus on a teaching experiment aimed at qualitatively analyzing which type teachers and peers would implement intervention, starting from mathematical models created by preservice teachers. Also, this study explains their reactions after intervention. The first objective of the study was classifying teacher and peer intervention types. These intervention types were divided into the intervention reason, intervention intention, and intervention area.

An analysis of the intervention reason in the modelling process found that both the teacher and peer interventions were caused by insufficient explanations and student error. In addition, the intervention caused by advancing the process was made only by the teacher. Other studies such as Kaiser and Stender (2013) state that throughout the modelling cycle teachers are given 
motivational encouragement and feedback like for example "you can solve this problem" or "you are on the right track, keep going". Tropper et al. (2015) found that teacher interventions are generally caused by teacher expectations, advancing the progress and student questions. In this study, motivational-type interventions arising from teacher expectations and student questions were not encountered. The reason for this distinction in the studies is thought to be because the intervention in our study occurred during the model sharing, not during the model producing. In the model sharing process, students can in general comment, question, and criticize various perspectives and at the same time learn to receive criticism with questions like "how will we explain?", "where did we make a mistake?". Studies suggest that peer assessments support both their own and their peers' learning and critical thinking skills (Li et al., 2019; Timmerman, 2004). In this study, it was observed that the participants learned to ask questions to each other during each modelling cycle of the mathematical modelling process such as "how do we explain this here?", "is it valid?" or "can it be generalized?". These questions could give pre-service teachers a chance to revise, develop, change and compare the models they create in accordance with Zawojewski (2013).

In terms of the intervention intention, it was determined that teacher interventions were identified under the categories of diagnosis, hint and feedback. Similarly, it was noticed that interventions with a heuristic-type question were analyzed in a study conducted by Leiß and Wiegand (2005), whereas the intentions for giving feedback and hints were observed and classified through a study by Van de Pol et al. (2010). In fact, all three types of interventions were researched in the study previously mentioned by Tropper et al. (2015). While the interventions used by the teachers in the present study were mostly diagnostic, followed by guided feedback and hints/suggestions, the study by Tropper et al. (2015) observed more hint and feedback interventions than diagnostic interventions. This is thought to be due again to the intervention taking place during the model sharing stage, not during the model producing stage. Unlike other studies, peer intervention intentions were determined to be mostly for diagnosis and then for feedback. This is a natural and expected situation because hints are put forward by people who are more skilled and experienced in the field (especially teachers) (Tropper et al., 2015; Van de Pol et al., 2010). In other words, the participants themselves may not have intervened to offer hints since they have almost the same level of qualifications as their peers. However, further research can show perhaps whether more interventions are in fact observed when the pre-service teachers' experience increases in mathematical modelling.

With respect to the intervention area, teacher interventions occurred throughout the entire modelling cycle. The peer interventions, however, came primarily the validity of real model (presenting findings, assumptions) and real results. This situation may derive from the teacher having more knowledge and experience in abstract modelling and mathematics while the peers tend to feel more comfortable and confident interpreting concrete aspects as they relate to real life. Accordingly, in mathematical modelling studies, throughout the stages of structuring / simplifying the real model and verifying the real results and testing its validity, group studies or peer support are significant (Biccard \&Wessels, 2011; Maaß, 2006) but students also need teacher support especially in the stages of producing and solving mathematical models. Similarly, in the study by Kaiser and Stender (2013), teachers support direct modeling competencies and mathematical content by asking questions such as "Can you create the model? Did you set the variables? What are the relationships between the variables?"

The second objective of the research was observing how the participants act in the modelling cycles in response to teacher and peer interventions. In this study there were primarily dialogues that involved questions such as "are the real models, mathematical models, mathematical results and real results valid mathematically? Are they valid in real life? Is the data set consistent? Can they be generalizable?" In these situations, the interventions discussed the validity of all the models and results, the generalizability of the proposed mathematical models and the consistency of the mathematical results. As a result of the intervention by the teacher or peer on the real model, the pre-service teachers demonstrated two different general behaviors. First is that they tended to revise the real model when they thought that the real model was not mathematically valid. The second is that when the assumptions were put forward and they thought that they were valid in real life, the pre-service teachers tended to verify the real model amongst themselves. When the interventions about the mathematical model were analyzed, two situations typically occurred. The first was a process to determine whether the model was generalizable or not and the second is whether the model is valid in real life or not. In both cases, it was shown that the participants tended to revise the mathematical models that they obtained directly. The interventions related to the mathematical results were analyzed and three different situations emerged. Two of these found that if the mathematical result was not consistent, the participants either tended to revise the mathematical model or return to revise the real model. The third typical situation was, if the mathematical result is in fact consistent with the data set, the participants went through a self-verification process related to the mathematical result. Finally, two different situations were observed when there was an intervention during the real result. The first one is that the participants returned to the mathematical model and revised the model given the fact that the real result turned out not to be valid in real life. The second is that the modelling process was completed by sufficiently verifying the result because of the real validity. According to this, results of this study were consistent with the study results by Czocher (2018) in terms of need to be tested the validity of the real model, mathematical model, mathematical results and the real results. While Czocher (2018) emphasizes that validity should be discussed during each of the modeling stages, the current study shows how the validity should be tested in terms of both mathematical and real life. Furthermore, in the present study it was also determined that not only validity but also generalizability and consistency should be tested. Thus, with the interventions made, it was observed that the real model, the mathematical model, and the results were revised, changed, improved or verified. This, in turn, created a modelling process that was more accurate and meaningful by returning to the stages of structuring, modelling, solving the model, interpreting and testing its validity. 


\section{RECOMMENDATIONS}

These findings suggest that it is recommended that these interventions should be for diagnosis, advice or feedback rather than providing information. Also, in the modeling process, while peer support may be sufficient to test the validity of the real model and real results, teacher support is required to test the validity of the mathematical model and its results. While intervening, not only should the student be expected to make a mistake, but interventions can also be made in cases when they have difficulty in overcoming a stage or models need to be improved. According to the results of this study, it is recommended that teachers or peers consider the following questions so that they can support mathematical modelling process according to validity:

1. Is the real model valid mathematically?

2. Is the real model valid in real life?

3. Can the mathematical model be generalised?

4. Is the mathematical model valid mathematically?

5. Is the mathematical result consistent with the data set?

6. Is the real result valid in real life?

7. Is the real result valid mathematically?

Author contributions: All authors have sufficiently contributed to the study, and agreed with the results and conclusions. Funding: No funding source is reported for this study.

Declaration of interest: No conflict of interest is declared by authors.

\section{REFERENCES}

Anghileri, J. (2006). Scaffolding practices that enhance mathematics learning. Journal of Mathematics Teacher Education, 9, 33-52. https://doi.org/10.1007/s10857-006-9005-9

Anhalt, C. O., \& Cortez, R. (2016). Developing an understanding of mathematical modelling in secondary teacher preparation. Journal of Mathematics Teacher Education, 19, 523-545. https://doi.org/10.1007/s10857-015-9309-8

Biccard, P., \& Wessels D. C. J. (2011). Documenting the development of modelling competencies of grade 7 mathematics students. In G. Kaiser, W. Blum, R. B. Ferri, \& G. Stillman (Eds.), Trends in teaching and learning of mathematical modelling (pp. 375-383). Springer. https://doi.org/10.1007/978-94-007-0910-2_37

Blomhøj, M., \& Kjeldsen, T. H. (2006). Teaching mathematical modelling through project work. ZDM-The International Journal on Mathematics Education, 38(2), 163-177. https://doi.org/10.1007/BF02655887

Blum, W. (2002). ICMI study 14: Applications and modelling in mathematics education-Discussion document. Educational Studies in Mathematics, 51, 149-171. https://doi.org/10.1023/A:1022435827400

Blum, W. (2011). Can modelling be taught and learnt? Some answers from empirical research. In G. Kaiser, W. Blum, R. Borromeo Ferri, \& G. Stillman (Eds.), Trends in teaching and learning of mathematical modelling (pp. 15-30). Springer. https://doi.org/10.1007/978-94-007-0910-2_3

Blum, W., \& Borromeo Ferri, R. (2009). Mathematical modelling: Can it be taught and learnt? Journal of Mathematical Modelling and Application, 1(1), 45-58.

Blum, W., \& Leiß, D. (2007). How do teachers deal with modelling problems? In C. Haines, P. Galbraith, W. Blum, \& S. Khan (Eds.), Mathematical modelling: Education, engineering and economics (pp. 222-231). Horwood Publishing. https://doi.org/10.1533/9780857099419.5.221

Borromeo Ferri, R. (2006). Theoretical and empirical differentiations of phases in the modelling process. ZDM-The International Journal on Mathematics Education, 38(2), 86-95. https://doi.org/10.1007/BF02655883

Borromeo Ferri, R., (2010). On the influence of mathematical thinking styles on learners'modeling behavior. Journal für Mathematik-Didaktik, 31, 99-118. https://doi.org/10.1007/s13138-010-0009-8

Brand, S. (2014). Effects of a holistic versus an atomistic modelling approach on students'mathematical modelling competencies. In C. Nicol, P. Liljedahl, S. Oesterle, \& D. Allan (Eds.), Proceedings of the Joint Meeting of PME 38 and PME-NA 36 (Vol. 2, pp. 185191). PME.

Bukova Guzel, E. (2011). An examination of pre-service mathematics teachers' approaches to construct and solve mathematical modelling problems. Teaching Mathematics and Its Applications, 30(1), 19-36. https://doi.org/10.1093/teamat/hrq015

Common Core State Standards Initiative [CCSI]. (2010). Common core state standards for mathematics. National Governors Association Center for Best Practices and the Council of Chief State School Officers.

Czocher, J. A. (2018). How does verification activity contribute to the modelling process? Educational Studies in Mathematics, 99(2), 137-159. https://doi.org/10.1007/s10649-018-9833-4

Durandt, R., \& Lautenbach, G. (2020). Strategic support to students' competency development in the mathematical modelling process: A qualitative study. Perspectives in Education, 38(1), 211-223. https://doi.org/10.18820/2519593X/pie.v38i1.15 
Frejd, P., \& Ärlebäck, J. B. (2011). First results from a study investigating Swedish upper secondary students' mathematical modelling competencies. In G. Kaiser, W. Blum, R. Borromeo Ferri, \& G. Stillman (Eds.), Trends in teaching and learning of mathematical modelling (pp. 407-416). Springer. https://doi.org/10.1007/978-94-007-0910-2_40

Galbraith, P., \& Stillman, G. (2006). A framework for identifying student blockages during transitions in the modelling process. ZDM-The International Journal on Mathematics Education, 38(2), 143-162. https://doi.org/10.1007/BF02655886

Gatabi, A. R., \& Abdolahpour, K. (2013). Investigating students' modelling competency through grade, gender, and location. In B. Ubuz, C. Haser, \& M. A. Mariotti (Eds.), Proceedings of the 8th Congress of the European Society for Research in Mathematics Education CERME 8 (pp. 1070-1077). Middle East Technical University.

Gee, J. P. (2011). How to do discourse analysis: A toolkit. Routledge. https://doi.org/10.4324/9780203850992

Greefrath, G., \& Vorhölter, K. (2016). Teaching and learning mathematical modelling: Approaches and developments from German speaking countries. ICME-13 Topical Surveys, 1-42. https://doi.org/10.1007/978-3-319-45004-9_1

Grünewald, S. (2012, July). Acquirement of modelling competencies-First results of an empirical comparison of the effectiveness of a holistic respectively an atomistic approach to the development of (metacognitive) modelling competencies of students [Paper presentation]. The 12th International Congress on Mathematical Education. Seoul, Korea.

Gurel, Z. C. (2018). The investigation of mathematical modelling processes of pre-service mathematics teachers with cognitive perspective [Unpublished doctoral dissertation]. Ataturk University.

Holton, D., \& Thomas, G. (2001). Mathematical interactions and their influence on learning. In D. Clarke (Ed.), Perspectives on practice and meaning in mathematics and science classrooms (pp. 75-104). Kluwer. https://doi.org/10.1007/0-306-47228-7_5

Ji, X. (2012, July). A quasi-experimental study of high school students' mathematics modelling competence [Paper presentation]. The 12th International Congress on Mathematical Education. Seoul, Korea.

Kaiser, G., \& Brand, S. (2015). Modelling competencies: Past development and further perspectives. In G. A. Stillman, W. Blum, \& M. S. Biembengut (Eds.), Mathematical modelling in education research and practice (pp. 129-149). Springer. https://doi.org/10.1007/978-3-319-18272-8_10

Kaiser, G., \& Stender, P. (2013). Complex modelling problems in co-operative, self-directed learning environments. In G. A. Stillman, G. Kaiser, W. Blum, \& J. P. Brown (Eds.), Teaching mathematical modelling: Connecting to research and practice (pp. 611-620). Springer. https://doi.org/10.1007/978-94-007-6540-5_23

Leiß, D., \& Wiegand, B. (2005). A classification of teacher interventions in mathematics teaching. ZDM-The International Journal on Mathematics Education, 37(3), 240-245. https://doi.org/10.1007/s11858-005-0015-3

Lesh, R., \& Doerr, H. M. (2003). Foundations of a models and modelling perspective on mathematics teaching, learning and problem solving. In R. Lesh, \& H. M. Doerr (Eds.), Beyond constructivism: Models and modelling perspectives on mathematics problem solving, learning and teaching (pp. 3-33). Lawrance Erlbaum Associates Publishers.

Lingefjärd, T. (2006). Faces of mathematical modelling. ZDM-The International Journal on Mathematics Education, 38(2), 96-112. https://doi.org/10.1007/BF02655884

Maaß, K. (2006). What are modelling competencies? ZDM-The International Journal on Mathematics Education, 38(2), 113-142. https://doi.org/10.1007/BF02655885

Maaß, K. (2007). Modelling in class: What do we want the students to learn? In C. Haines, P. Galbraith, W. Blum, \& S. Khan (Eds.), Mathematical modelling: Education, engineering and economics (pp. 63-78). Horwood Publishing. https://doi.org/10.1533/9780857099419.2.63

Mayring, P. (2015). Qualitative content analysis: Theoretical background and procedures. In A. Bikner-Ahsbahs, C. Knipping, \& N. Presmeg (Eds.), Approaches to qualitative research in mathematics education (pp.365-380). Springer. https://doi.org/10.1007/978-94-017-9181-6_13

Ministry of National Education. (2013). Secondary school mathematics teaching program. Milli Eğitim Basımevi [National Education Printing House].

NCTM. (2000). Principles and standards for school mathematics. NCTM.

Niss, M., Blum, W., \& Galbraith, P. (2007). How to replace the word problems? In W. Blum, P. Galbraith, H-W. Henn, \& M. Niss (Eds.), Modelling and applications in mathematics education: The 14th ICMI study (pp. 3-32). Springer.

Schaap, S., Vos, P., \& Goedhart, M. (2011). Students overcoming blockages while building a mathematical model: Exploring a framework. In G. Kaiser, W. Blum, R. Borromeo Ferri, \& G. Stillman (Eds.), Trends in teaching and learning of mathematical modelling (pp. 137-146). Springer. https://doi.org/10.1007/978-94-007-0910-2_15

Steffe, L. P., \& Thompson, P. (2000). Teaching experiment methodology: Underlying principles and essential elements. In R. Lesh, \& A. E. Kelly (Eds.), Research design in mathematics and science education (pp. 267-306). Lawrance Erlbaum Associates Publishers.

Stender, P., \& Kaiser, G. (2015). Scaffolding in complex modelling situations. ZDM-The International Journal on Mathematics Education, 47, 1255-1267. https://doi.org/10.1007/s11858-015-0741-0

Timmerman, M. A. (2004). The influences of three interventions on prospective elementary teachers' beliefs about the knowledge base needed for teaching mathematics. School Science and Mathematics, 104(8), 369-382. https://doi.org/10.1111/j.19498594.2004.tb18003.x 
Tropper, N., Leiß, D., \& Hanze, M. (2015). Teachers' temporary support and worked-out examples as elements of scaffolding in mathematical modelling. ZDM-The International Journal on Mathematics Education, 47, $1225-1240$. https://doi.org/10.1007/s11858-015-0718-z

Turker, B., Saglam, Y., \& Umay, A. (2010). Preservice teachers'performances at mathematical modelling process and views on mathematical modelling. Procedia Social and Behavioral Sciences, 2, 4622-4628. https://doi.org/10.1016/j.sbspro.2010.03.740

Van de Pol, J., Volman, M., \& Beishuizen, J. (2010). Scaffolding in teacher-student interaction: A decade of research. Educational Psychology Review, 22(3), 271-297. https://doi.org/10.1007/s10648-010-9127-6

Wischgoll, A., Pauli, C., \& Reusser, K. (2015). Scaffolding-How can contingency lead to successful learning when dealing with errors? ZDM Mathematics Education, 47, 1147-1159. https://doi.org/10.1007/s11858-015-0714-3

Zawojewski, J. (2013). Problem solvings versus modelling. In R. Lesh, P. Galbraith, C. Haines, \& A. Hurford (Eds.), Modelling students' mathematical modelling competencies (pp. 237-243). Springer. https://doi.org/10.1007/978-94-007-6271-8_20 


\section{Appendix}

Temperature Values of the Last Five Years Belonging to $X$ (Code Name)

\begin{tabular}{|c|c|c|c|c|c|c|c|c|c|c|c|c|c|}
\hline Years & & January & February & March & April & May & June & July & August & September & October & November & December \\
\hline & Min. & -17.6 & -16.2 & -8.9 & 0 & 7.5 & 7.7 & 9.2 & 12.2 & 8.4 & 3.1 & -2.8 & -6.9 \\
\hline \multirow[t]{3}{*}{2012} & Mean & -1.8 & -4.9 & 1.4 & 12.6 & 16.5 & 21.4 & 24.3 & 24.3 & 20.4 & 13.6 & 8 & 2.1 \\
\hline & Max. & 8.6 & 7 & 13.7 & 26.1 & 33.8 & 33.8 & 39.1 & 37.1 & 33.5 & 30.8 & 20.3 & 12.2 \\
\hline & Min. & -17.1 & -5.7 & -7.4 & 1.1 & 7.4 & 7.6 & 11.2 & 12.1 & 6.2 & -0.2 & -2.3 & -12 \\
\hline \multirow[t]{3}{*}{2013} & Mean & -2.2 & 3.2 & 6.1 & 12.5 & 17 & 20.4 & 23.4 & 24 & 18.5 & 11.8 & 8 & -3.6 \\
\hline & Max. & 9.2 & 14.5 & 19.8 & 28 & 29 & 34.2 & 35.3 & 35.7 & 33.4 & 27.7 & 20.7 & 7.6 \\
\hline & Min. & -13.6 & -11.7 & -5.6 & -2.5 & 5.8 & 7.9 & 13.9 & 14.2 & 6.2 & 0.3 & -4.4 & -5.5 \\
\hline \multirow[t]{3}{*}{2014} & Mean & -0.5 & 3 & 8 & 12.6 & 16.6 & 20.7 & 25.6 & 26.4 & 20.1 & 12.2 & 5.1 & 4.6 \\
\hline & Max. & 11.2 & 16.8 & 20.3 & 25.8 & 30.4 & 34.1 & 37.8 & 38.6 & 35.3 & 26.2 & 15.7 & 13.3 \\
\hline & Min. & -14.3 & -6.1 & -5 & -3.6 & 4.6 & 10.1 & 12.9 & 13.2 & 11.2 & 3.9 & -3.8 & -7.9 \\
\hline \multirow[t]{3}{*}{2015} & Mean & -2.8 & 2.3 & 6.1 & 9.5 & 15.8 & 21.2 & 25.3 & 26.2 & 23 & 13.2 & 6.6 & -1 \\
\hline & Max. & 11.7 & 13.2 & 17.4 & 24.4 & 31.1 & 33.5 & 39.6 & 38.4 & 36 & 27.2 & 19 & 10.5 \\
\hline & Min. & -20.6 & -12.1 & -4.7 & -3 & 5.8 & 7.1 & 12.4 & 14.5 & 3.3 & 1 & -7.4 & -18.4 \\
\hline \multirow[t]{3}{*}{2016} & Mean & -2.6 & 1.1 & 6.8 & 13.2 & 14.8 & 20.2 & 24.1 & 26.1 & 17.7 & 13.2 & 4.5 & -2.9 \\
\hline & Max. & 9.3 & 16.4 & 18.7 & 25.9 & 27.3 & 35 & 36 & 37.5 & 32.8 & 28.3 & 21.4 & 8.1 \\
\hline & Min. & -13.6 & -12.4 & -4.1 & -2.4 & 5.4 & 7.9 & 12 & 16.2 & 10.5 & 2.7 & -6.5 & -5.5 \\
\hline \multirow[t]{2}{*}{2017} & Mean & -2.6 & -1.4 & 6.3 & 10.7 & 15.2 & 21 & 26.1 & 27 & 22.8 & 12.6 & 5.7 & 3 \\
\hline & Max. & 8.9 & 14.1 & 18 & 24.9 & 28.4 & 35.8 & 38.3 & 39.3 & 36.4 & 24.5 & 18.1 & 14.4 \\
\hline
\end{tabular}

